\title{
Religião comparada, taxonomias e filosofias da ciência do século XIX: Chantepie de la Saussaye e Tiele
}

\author{
Comparative Religion, Taxonomies And 19th Century Philosophies \\ Of Science: Chantepie De La Saussaye And Tiele
}

\author{
Thomas Ryba * \\ Tradução: José Martins dos Santos Neto **
}

\begin{abstract}
Resumo
É um fato amplamente reconhecido que o filósofo Hegel exerceu influência marcante no desenvolvimento inicial das fenomenologias da religião. O presente artigo pretende possibilitar uma leitura aprofundada das fenomenologias de C.P. Tiele e P.D. Chantepie de la Saussaye de modo a demonstrar a extensão da influência de Hegel em seu pensamento. Essa demonstração procede de forma desconstrutiva (no sentido heideggeriano e não derrideano do termo), estabelecendo em primeiro lugar a questionabilidade da reivindicação de cada pensador na representação de uma ciência unitária da religião e, em segundo, mostrando as oposições entre as respectivas noções de taxonomia e de ciência da religião. $\mathrm{O}$ artigo conclui sugerindo que, embora os pensadores em questão possam ter se apropriado de alguns elementos evolutivos, suas respectivas concepções de ciência também foram influenciadas pela visão "recebida" subjacente aos escritos de cientistas fenomenólogos como Robison, Hamilton e Whewell.
\end{abstract}

\begin{abstract}
It has been generally recognized that an important influence on the development of early phenomenologies of religion was Hegel. It is the purpose of this paper to provide a deep reading of the phenomenologies of C.P. Tiele and P.D. Chantepie de la Saussaye in order to demonstrate the extent of Hegel's influence on their thought. This demonstration proceeds deconstructively (in the Heideggerian, not the Derridean,sense) to establish (a) the questionability of each thinker's claim to represent a unitary science of religion and to show (b) the oppositions between the respective notions of taxonomy and the notions of science of religion. The paper concludes by suggesting that although both thinkers may have appropriated some Hegelian evolutionary elements, their respective conceptions of science were also influenced by the "received" view that lay behind the writings of scientific phenomenologists such as Robison, Hamilton and Whewell.
\end{abstract}

\footnotetext{
Artigo submetido em 17 de janeiro de 2021 e aprovado em 29 de janeiro de 2021. Este artigo foi originalmente publicado na revista Numen, v. 48, n. 3, p. 309-338, 2001, e é aqui reproduzido com autorização do próprio autor. Foram realizadas adequações em conformidade com as normas da ABNT.

* Professor sênior de Ciência da Religião (Religious Studies) e de Filosofia na Universidade Purdue, localizada em West Lafayette, Indiana. País de origem: Estados Unidos. ORCID: oooo-0oo3-2793-4308. E-mail: methexis@sttomspurdue.org

** Doutor em Filosofia pela Universidade Complutense de Madrid. Mestre em Estudos Linguísticos pela Central Michigan University. Professor colaborador do PPGCR PUC Minas. País de origem: Brasil. ORCID: oooo-ooo3-4572120X. E-mail: biotoque1961@gmail.com
} 


\section{Introdução}

Ao longo da relativamente breve história comparada da religião, acadêmicos como Jastrow, Jordan, Smith e Paden fizeram inúmeros comentários sobre o gosto dos estudiosos pela apropriação das estratégias de taxonomias e métodos de outras ciências, como botânica, zoologia, anatomia comparada, linguística, etc. (JASTROW, 1981/1901; JORDAN, 1986/1905; BRAUN, 2000; PADEN, 1994). Algumas vezes essa apropriação tem sido consistente com as mais amplas suposições filosóficas das "disciplinas de empréstimo". Na maioria das vezes, no entanto, essa apropriação tem sido sincrética e fragmentada, uma bricolagem improvisada de métodos classificatórios e objetivos ideológicos fundamentalmente em desacordo uns com os outros. Quando a apropriação de métodos taxonômicos extradisciplinares se mostraram úteis, a incongruência absoluta de acoplá-los a ideologias estranhas fez com que essas ideologias parecessem inúteis. Com frequência, a caridade interpretativa projetou uma unidade por trás desses sincretismos, mesmo quando as oposições não podiam ser reconciliadas.

O objetivo deste artigo é esboçar uma arqueologia desconstrutiva de dois exemplos da ciência da religião do século XIX de modo a descobrir as filosofias científicas que estão por trás de suas respectivas ciencias religiosas e métodos taxonômicos. Isso traduz uma distinção projetada para atender ao argumento desenvolvido a seguir. Existe uma distinção entre a dimensão metacientífica desses estudiosos da religião compreendendo os seus trabalhos e a dimensão intracientífica dos mesmos. A primeira distinção aborda a seguinte questão: “o que esses estudiosos da religião concebem como ciência e, mais particularmente, como ciência da religião?” A segunda distinção, por sua vez, aborda o seguinte: "como os estudos comparativos e a classificação das religiões podem ser realizados no escopo de suas concepções da ciência da religião". Dessas duas questões emerge uma terceira considerada de suma importância para o propósito deste artigo, a saber "qual é exatamente a relação entre os aspectos metacientíficos e intracientíficos da taxonomia praticada por esses estudiosos da religião?” As ciências da religião a serem discutidas são as de P. D. Chantepie e de C. P. Tiele. 
Obviamente, muito se tem escrito sobre os métodos religiosos e as teorias desses dois estudiosos da religião. Nesse sentido, legitimamente se pode colocar a questão: "Por que outro tratamento ainda se faz necessário?”. Com toda a consternação implícita nessa pergunta, minha única defesa é que, pelo que eu saiba, não há notícias de alguém que tenha formulado a questão precisamente dessa forma. Justamente porque essa pergunta não foi formulada por ninguém até o momento, acredito que um aspecto da natureza sincrética da religião comparativa tenha sido negligenciado. Essa miopia parece ser razão suficiente para se retornarem a essas fontes, mesmo que, ao fazê-lo, estejamos, de certo modo, agindo em consonância com o conhecido provérbio bíblico do cão voltando ao seu vômito $(2 \mathrm{Pe} 2,22)$.

A organização do restante deste artigo segue em três partes. Primeiramente farei uma leitura atenta daquelas partes do Manual de Chantepie e dos Elementos de Tiele que nos apresentam formulações da ciência da religião e do papel que a taxonomia desempenha em cada uma delas. Em segundo lugar, descreverei as oposições que ocorrem em cada formulação e mostrarei como essas oposições (a) minam suas alegações de apresentarem unitariamente as ciências da religião e (b) conflitam com os métodos taxonômicos propostos. Por fim, concluirei com algumas breves observações sobre as possíveis lições a serem aprendidas em decorrência de tudo o que foi exposto.

\section{Leituras aproximadas de duas Ciências da Religião do século XIX}

\subsection{Ciência e taxonomia no Manual de Ciência da Religião de Chantepie de la Saussaye}

Metacientificamente, Chantepie de la Saussaye (1891) conceitua sua "ciência da religião" contra o pano de fundo do entendimento hegeliano da filosofia e da compreensão alemã da ideia de Religionswissenschaft. De acordo com Chantepie (1891), quatro componentes foram necessários para a realização dessa nova ciência: 
a) três modos / metodologias para seu estudo (as abordagens “metafísicas, psicológicas e históricas”);

b) uma filosofia da história, particularmente a história da civilização (para revelar "a conexão da religião com os outros lados da vida”),

c) o conteúdo de seu assunto ("arqueologia, filologia, etnografia, psicologia das nações, mitologia e folclore”), e (4) seu objeto - o estudo da religião em sua essência e manifestações (CHANTEPIE, 1891, p. 3-8). ${ }^{1}$

Ao elaborar seu posicionamento intracientífico, Chantepie estipula que as relações específicas definem os limites entre a ciência da religião e a teologia. Assim, (1) "a unidade da religião na variedade de suas formas ... é pressuposta pela ciência da religião" (CHANTEPIE, 1891, p. 9); (2) “A ciência da religião" e a teologia "seguem caminhos distintos ... e (3) têm objetos distintos" embora (4) "eles devem se ajudar mutuamente" (CHANTEPIE, 1891, p. 10). O campo-objeto da ciência religiosa é contrastado com o da teologia partidária, que se acha ligada a uma única religião histórica. Não obstante, ele sugere que seus objetos não são totalmente incomunicáveis.

No que diz respeito às fontes históricas para sua noção da ciência da religião, Chantepie (1891) credita Hegel como o fundador da disciplina porque em suas Lectures on the Philosophy of Religion ele propôs, para os seus estudos, os três modos - “o metafísico [ou lógico], o psicológico e o histórico". Essa afirmação sobre o topos é um pouco simplificada, no entanto. No corpus hegeliano, existem na verdade quatro locais que têm significancia para uma compreensão da ciência da religião de Chantepie: aquele que Chantepie menciona explicitamente (nomeadamente, Hegel's Lectures on the Philosophy of Religion) e três que permanecem não mencionados mas são, no entanto, alusivamente referenciados na forma como ele descreve a sua ciência. As fontes ocultas são a Encyclopedia of the Philosophical Sciences, Lectures on the Philosophy of History and the Phenomenology of Spirit. Sem essas outras

\footnotetext{
${ }^{1}$ Por uma questão de economia, as citações de páginas subsequentes nesta seção seguirão entre parênteses, mas com o nome do autor e a data de publicação suprimidos.

* Nota do tradutor: Embora tenhamos traduzido a nota do autor, a fim de mantermos a sequência numérica de acordo com o texto original, não seguiremos o que aqui é enunciado, de modo que, nesta tradução, inserimos as referências no próprio corpo do texto, sob a forma do sistema autor-data, em consonância às normas da ABNT.
} 
fontes, as razões para a reivindicação de Chantepie de que nem todos os três modos são uma parte da ciência filosófica não seriam inteligíveis.

Segundo Chantepie, apenas as abordagens metafísicas e psicológicas da religião são formalmente filosóficas, sendo a história (segundo Hegel) tratada como o material de análises filosóficas, o que não é propriamente filosófico. A análise da essência da religião corresponde à filosofa da religião (subdividida em metafísica e psicologia da religião), enquanto a descrição das manifestações dessa essência na cultura da humanidade corresponde a história da religião (subdividida em etnografia e história) com a taxonomia (ou "a coleta e o agrupamento de vários fenômenos"), formando assim, a "transição da história à filosofia da religião" (CHANTEPIE, 1891, p. 8).

Chantepie é muito direto ao afirmar que sua única preocupação no Manual é histórica. A preocupação filosófica - que trataria a religião segundo suas “dimensões subjetivas e objetivas" - está reservada à filosofia da religião (CHANTEPIE, 1891, p. 8). Mas ele imediatamente vicia essa segregação de assunto ao incluir a fenomenologia da religião no Manual, como ele afirma, para expandir o caráter restritivo de sua discussão, apesar das dificuldades filosóficas óbvias (CHANTEPIE, 1891, p. 8). A razão pela qual isso é uma espécie de violação de sua esquematização pretendida é que o suposto modelo hegeliano para a organização de Chantepie torna essa sequência problemática. ${ }^{2}$

Na classificação das religiões, Chantepie novamente faz referência a Hegel, comprometendo-se com os princípios taxonômicos que Hegel endossa, mas sem aceitar os princípios taxonômicos hegelianos. Seguindo Hegel, Chantepie argumenta que as divisões taxonômicas no estudo da religião não devem ser feitas de acordo com o "sentido subjetivo", mas deve refletir "a divisão necessária no sentido objetivo de natureza da mente.” (CHANTEPIE, 1891, p. 50-51). Isso significa que qualquer arranjo taxonômico das religiões deve refletir "as etapas do desenvolvimento da ideia e ao mesmo tempo de sua manifestação concreta” (CHANTEPIE, 1891, p. 51). Assim, a taxonomia deveria

\footnotetext{
${ }^{2}$ Com toda a honestidade, a peculiaridade dessa organização ainda pode ser legitimada em bases hegelianas, argumentando que, embora Chantepie exclua a análise filosófica de seu Manual, ele com certeza fornece uma história filosófica (no sentido hegeliano). Mesmo nesse caso suas ações se opõem às suas intenções declaradas e esse conflito de motivos indica que questões filosóficas mais profundas estão abaixo da superfície instável do texto. (Veja a discussão posterior neste artigo e, especialmente Hegel (1956).
} 
refletir (1) o desenvolvimento da ideia de religião em sua unidade, (2) o desenvolvimento das manifestações multifacetadas da religião, e (3) as relações entre 1 e 2. A noção de desenvolvimento requer um arranjo sequencial do mais baixo para o mais alto, embora Chantepie não pense que Hegel tenha proposto qualquer arranjo que fosse adequado. Chantepie, reconhecendo a "enorme importância”, consistência e completude das abordagens naturalísticas - ou, como ele mesmo afirma, abordagens "mecânicas" para a evolução do suborgânico, orgânico e superorgânico, em última instância rejeita, sob bases axiológicas, teológicas e históricas muito vagas, qualquer abordagem radical para o estudo da religião (CHANTEPIE, 1891, p. 10-11). Ele recorre a um tipo de desenvolvimentismo que não é completamente naturalista.

De acordo com Chantepie, uma nominalização completa dos dados não pode resultar em classificações científicas. O que se faz necessário é a taxonomia com base em características essenciais, sendo que as duas variedades reconhecidas são a genealogia e a morfologia (CHANTEPIE, 1891, p. 51). A abordagem genealógica, embora "tenha produzido abundantes frutos", é simplesmente tão boa quanto o discernimento relativo às "características principais" da religião. Nesse sentido, portanto, só são úteis como objetos práticos de levantamentos históricos. 3 (CHANTEPIE, 1891, p. 51-52). Por “características principais”, Chantepie intenciona tudo o que há de mais notável sobre um objetivo prático atual, mas o que pode não ser de fato essencial para ele. O problema é que fazer uma genealogia das religiões definida por traços notáveis é tomar como objeto uma sopa genética de traços ambientais, as vicissitudes da cultura e da história, das quais é difícil separar aqueles traços que são exclusivamente religiosos. Por causa de suas misturas de parentesco histórico, as religiões carregam muitos segmentos genéticos que não são religiosos. A morfologia, porque se baseia em qualidades essenciais, é mais filosófica no sentido hegeliano e, portanto, deve ser preferida. (CHANTEPIE, 1891, p. 51).

\footnotetext{
3 O uso que Chantepie faz do termo "prático" aqui pode ter a intenção de espelhar a noção hegeliana pragmática da história assim como as reconstruç̃es presentes do passado com base nos valores do presente. Assim, as "características principais" de tais recontruções genealógicas podem não ser baseados nas características necessárias das coisas (ou eventos históricos), como eram, mas de acordo com os valores e interesses que lhes impomos a partir de nosso ponto de vista atual . Esse tipo de história / genealogia pode resultar na descoberta do presente no passado, uma descoberta que negligencia a própria unicidade e - para empregar um termo usado em demasia nestes tempos pósmodernos - alteridade. Somente quando as "futuras características" escolhidas coincidirem com as características essenciais, nos aproximaremos de fato da abordagem que Chantepie defende. (Ver: HEGEL, 1965, p. 5-7).
} 
Entre os morphai que Chantepie lista como possíveis (mas não necessariamente) definidores dos taxons religiosos são os seguintes: verdadeiro-falso, natural-revelado, popular-pessoal, monoteísta-político-teísta, mitológico-dogmático, racionalista-estético-ético, extático-deprimido, particular-universal e o natural-moral como o mais importante deles. (CHANTEPIE, 1891, p. 53-54). Embora não dê nenhum assentimento irrestrito a qualquer taxonomia particular, Chantepie pensa que o consenso acadêmico sobre a distinção entre religião natural, de um lado, e intelectual-moral, por outro, tem uma validade que foi originalmente pressagiada por Hegel (CHANTEPIE, 1891, p. 56).

A introdução da noção de fenomenologia na discussão dos dados históricos coloca problemas únicos, particularmente na medida que Chantepie identifica a inspiração de sua ciência da religião como Hegel, uma inspiração que deveria excluir a fenomenologia tanto das divisões filosóficas da Lógica ou da Filosofia da Natureza, por um lado, ou da História, por outro. Mas - com as devidas desculpas - Chantepie coloca sua discussão da fenomenologia precisamente no âmbito da história, o último lugar, de acordo com a filosofia hegeliana da ciência, a que deveria pertencer. Isso é estranho em si, mas a maneira como Chantepie apresenta o conteúdo dessa fenomenologia torna ainda mais estranha sua valorização de Hegel. Vejamos brevemente a função que Chantepie atribui à fenomenologia.

Na defesa da formulação hegeliana, Chantepie descreve a fenomenologia da religião de tal modo a sugerir que ela poderia achar sua colocação na sequência das ciências do mesmo modo que o da fenomenologia do espírito na Encyclopedia of the Philosophical Sciences. De sua descrição da religião como conectada à psicologia, "os fatos da consciência humana”, e como algo a ser explicado à base dos processos e relações mentais internas, pode-se pensar que é essa dimensão que Chantepie escolheria abordar, mesmo fora de lugar como seria o caso, em seu Manual (CHANTEPIE, 1891, p. 67). Mas não foi esse o caso. $\mathrm{Na}$ tentativa de contornar o círculo de definição que atormentou as fenomenologias de todos os matizes, Chantepie adia a "definição precisa do caráter dos fenômenos religiosos à filosofia e ao conteúdo(s) ... [ele mesmo] com 
a classificação do material etnográfico e histórico mais importante conectado com os fenômenos da religião" (CHANTEPIE, 1891, p. 67). Percebe-se, claramente, que houve uma mudança no entendimento de Chantepie no que se refere à sua tarefa. O que iniciou principalmente como uma obra de história, veio a se tornar uma obra de taxonomia, compreendida como a disciplina que faz ponte entre a história e a filosofia.

\subsection{Ciência e Morfologia na obra Elements of the Science of Religion, de C. P. Tiele}

A ciência da religião estava tão suficientemente estabelecida na época em que Tiele escreveu os Elementos que ele poderia alegar com plausibilidade que essa área do conhecimento havia "garantido em si um lugar entre as várias ciências da mente humana" (TIELE, 1899, p. 2).4 Mas o que exatamente Tiele quer dizer com "ciência da religião"? Tomando o termo "religião" primeiramente, Tiele alega não ter preconceitos sobre o objeto de sua ciência; este objeto, "o que a religião realmente é em sua essência", só pode ser "verificada como resultado da investigação como um todo" (TIELE, 1899, p. 4). Ademais, alguma estimativa aproximada se faz necessária.

Para atender a essa demanda, Tiele fornece nada mais do que uma definição operacional recursiva que - por causa de sua estrutura de oposição antecipa outras abordagens de definição no âmbito da Linhagem Saussuriana.5 A religião, de acordo com esta definição operacional "é o agregado de todos aqueles fenômenos que são invariavelmente denominados de religiosos, em contradição com a ética, a estética, a política e outros", isto é, “as manifestações da mente humana em palavras, atos, costumes e instituições que testemunham... (a) crença no sobre-humano, tornando possível (alguém)... relacionar-se com o mesmo" (TIELE, 1899, p. 4). Qualquer coisa que esteja além do "alcance do perceptível", além da "razão científica ou filosófica", não é

\footnotetext{
${ }_{4}$ Novamente, por uma questão de economia, as citações de páginas subsequentes nesta seção seguirão entre parênteses, mas com autor e data suprimidos.

*Nota do tradutor: Vale, aqui, a mesma observação já feita para a nota de número 1.

5 A noção evidente aqui é que a religião como um setor da cultura / experiência humana pode ser mais bem conhecida por uma espécie de via negativa. Ao subtrair todos os traços essenciais dos setores culturais, o que restar será presumivelmente religioso. A estranheza de tal sugestão deriva do fato de que para conhecer a religião exaustivamente é preciso primeiro conhecer exaustivamente as outras partes da cultura. Isso se assemelha à noção saussuriana de que o significado completo de uma palavra é conhecido apenas em oposição a todos os outros membros do campo semântico do qual faz parte. Idealmente, isso pode ser verdade, mas dificilmente é a maneira como aprendemos um idioma ou chegamos a uma apreciação do que "religião" denota.
} 
fenômeno para essa nova ciencia, mas para Tiele, é uma questão em aberto se a metafísica ou a filosofia podem tomar qualquer coisa além da percepção humana como seus objetos (TIELE, 1899, p. 4-5). A ciência da religião não aceita tais objetos; seus objetos são as tematizações humanas do supra-humano, as crenças da humanidade no sobre-humano. Estão dentro do alcance da ciência porque são fenômenos "históricos-psicológico, sociais e o fenômeno humano como um todo" (TIELE, 1899, p. 5).

O que Tiele entende por ciência, então? Ele não pretende nada que seja "presunçoso", nada que em suas afirmações ou hipóteses ultrapasse seus próprios métodos; em vez disso, ele compreende por "ciência” tudo o que possa ser aprendido por "um método sólido e crítico", complementar ao seu campo independente (TIELE, 1899, p. 5). Para uma ciência ser uma ciência tieleana, ela deve possuir quatro características:

a) um domínio suficientemente amplo;

b) "uma unidade que abrange a multiplicidade de fatos pertencentes a esse domínio";

c) "uma conexão interna destes fatos que nos permitam sujeitá-los a uma classificação cuidadosa e tirar deles inferências frutíferas";

d) resultados frutíferos importantes e verdadeiros com base em a, b e c (TIELE, 1899, p. 6).

Assim, o domínio da religião se reporta a todos os fenômenos religiosos humanos; a unidade é a unicidade da mente humana refratada de forma diferente atavés desses fenômenos em diferentes estágios de desenvolvimento; a conexão interna é a classificação científica das religiões e a importância deste estudo é "auto-manifesta" "devido ao valor de seu tema” (TIELE, 1899, p. 6). Os objetos internos e exteriores desta nova ciência correspondem às divisões do Ensaio. A parte morfológica - ou ôntica - corresponde as formas externas da religião, "as constantes mudanças de forma são resultantes de uma evolução sempre progressiva”, e a parte ontológica corresponde à unidade interna, "o 
elemento inalterável em transito e em constante alteração de formas..., a origem e a própria natureza da religião" (TIELE, 1899, p. 27). ${ }^{6}$

Embora tal ciência da religião possa parecer ameaçadora para os religiosos e também anti-religiosos, os novos cientistas da religião não se preocupam com essas suspeitas, mas sujeitam os fenômenos religiosos "a uma investigação sem preconceitos" para entender seus "fundamentos", suas leis de "crescimento e decadência"; em outras palavras, assumem "uma posição objetiva para todos, (“imperfeitamente" reveladas) formas de religião”, mas as distinguem "cuidadosamente da própria religião" para chegar mais perto da sua fonte (TIELE, 1899, p. 9). Esta nova ciência não deve ser confundida com a teologia, cujos objetivos são "estudar, explicar, justificar e... purificar”; em vez disso, seus objetivos são "investigar e explicar... para saber o que a religião é,e por que somos religiosos" (TIELE, 1899, p. 12).

Aqui, a objetividade do filólogo é o principal modelo de objetividade na ciência da religião: "todas as formas religiosas são simplesmente objetos de investigação, diferentes linguagens em que o espírito religioso se expressa”, com tão pouca preocupação para com as diferenças entre os religiosamente ortodoxos e os heterodoxos como o filólogo se preocupa para com as diferenças entre a estrutura gramatical do finlandês e do árabe (TIELE, 1899, p. 9). De acordo com Tiele, a objetividade não acarreta necessariamente ceticismo como alguns defenderam; os objetivos da ciência da religião podem ser alcançados por qualquer pessoa que mantenha a objetividade em seu estudo. $\mathrm{O}$ compromisso com uma tradição religiosa não impede uma apreciação científica de outras formas religiosas (TIELE, 1899, p. 11). Nem a "defesa" ardorosa da

\footnotetext{
${ }^{6}$ A distinção entre o ôntico e o ontológico que apresentei, aqui, não é de Tiele, mas de Martin Heidegger, que a usa de maneira semelhante a Tiele. A passagem a seguir deixa essas semelhanças claras:

A ciência é o fundamento da revelação, por pura revelação, das regiões autocontidas de tudo o que é, ou conforme o caso, do Ser. ... A ciência ôntica tematiza qualquer ser dado, que de certa forma já é anunciado antes da divulgação científica. Chamamos as ciências de tudo o que é dado - de um positum - ciências positivas. A objetificação de tudo o que eles tematizam é uma continuação direta da atitude pré-científica em relação a esse ser. A ontologia, ou ciência do Ser, por outro lado, exige uma mudança fundamental de visão: de tudo o que (concretamente) é para o Ser. E essa mudança, no entanto, mantém tudo o que está em vista, exceto por uma atitude modificada... Toda a ciência positiva é absolutamente, não relativamente, diferente da filosofia.

Lida na pespctiva heideggeriana, a distinção de Tiele entre morfologia e ontologia é a introdução intracientífica da distinção entre a filosofia heideggeriana e as ciências individuais. Historicamente, a distinção entre morfologia e a ontologia como caracterizando a estrutura metacientífica de toda ciência precede Heidegger (1976). No entanto, Heidegger (1976), ao tentar salvar a filosofia, a torna órfã da ciência criança, iniciando agora o processo que culmina em sua (suposta) morte. Como veremos abaixo, a visão mais antiga da estrutura metacientífica das ciências é aquela que Tiele segue mais de perto. (Veja: HEIDEGGER, 1976, p. 6).
} 
crença, avaliando a superioridade dessas formas, nem a reforma religiosa são, per se, os objetivos do estudioso da religião, embora as investigações de ciencia religiosa possam render frutos práticos ao fornecer uma demonstração imparcial de que a religião está "enraizada na... natureza íntima da maioria da humanidade" (TIELE, 1899, p. 10).

Com respeito ao aninhamento de determinada ciência da religião, Tiele distingue o "estudo geral e histórico das religiões", por um lado, e as teologias especiais, por outro lado, da ciência da religião. O primeiro "observa, coleta, combina, compara e classifica os fatos em sua ordem de desenvolvimento" enquanto o segundo diz respeito a legitimação religiosa - conforme descrito acima. A ciência da religião não se confunde com nenhum dos dois, mas de forma independente utiliza suas descobertas "com o propósito de determinar o que a religião manifestada em todos esses fenômenos essencialmente é, e de onde ela procede" formando, desse modo, o "topo, ou... o centro para o qual todas (essas ciências) convergem" (TIELE, 1899, p. 13).

A ciência da religião de Tiele é, portanto, uma ciência especial e não, ao contrário de algumas das afirmações de Chantepie - uma parte da filosofia geral, embora possa, do modo o mais literal possível, ser considerada "a filosofia de religião", porque se preocupa com a "parte filosófica da investigação dos fenômenos religiosos" como a ciência que busca "penetrar" até os fundamentos dos fenômenos religiosos (TIELE, 1899, p. 15). Isso é filosofia da religião com um novo sentido, uma filosofia "reformada" pelo estado atual da ciência, embora como uma nova filosofia científica não vem a considerar a religião simplesmente nem como um "produto natural ou artificial” (TIELE, 1899, p. 15-16), nem tampouco pode essa ciência da religião "aplicar os métodos exatos de as ciências naturais” sem "autoengano e dolorosa decepção” (TIELE, 1899, p. 16).

Quais são, então, os métodos desta nova ciência, de acordo com Cornélio Petrus Tiele? Esse teólogo e estudioso das religiões prossegue dizendo o que esses métodos de fato não são. Eles não são exclusivamente empírico positivistas, adequados apenas para a apuração e classificação dos fatos, mas “impotentes para explicá-los"; eles não são exclusivamente históricos - 
resultando apenas em particularidades; eles não são em absoluto genéticoespeculativo - "uma mistura de história e filosofia" carente de qualquer unidade; nem são puramente especulativos, sem amarrações que os ancorem à terra (TIELE, 1899, p. 18). Surpreendentemente, Tiele descreve os métodos da ciência da religião como dedutivos e também como um dos mais antigos e confiáveis dos instrumentos epistêmicos do ocidente.

O método religioso-dedutivo não opera nem exclusivamente nem aprioristicamente mas pressupõe "os resultados produzidos por indução, por métodos empíricos, históricos e comparativos" de modo a operar a partir de "fenômenos religiosos" externos (ou as" manifestações externas da religião") em direção à descoberta de uma psicologia comum ou o “ser” (TIELE, 1899, p. 18). Os estudiosos da religião devem, portanto, “dominar" os dados mesmo que não sejam responsáveis por exauri-los como um todo (TIELE, 1899, p. 19). O resultado deste movimento dedutivo é a construção de um sistema naturalista para a explicação da psique religiosa, um sistema cujas explicações deve ser submetido a "fatos sólidos" (TIELE, 1899, p. 20). Um ponto central para a explicação da consciência religiosa são os sentimentos religiosos, "tudo... que este estado de espírito" abarca e ao qual dá expressão, o conjunto completo de palavras e ações religiosas de acordo com o significado atribuído a elas pelos crentes (TIELE, 1899, p. 25). "Na... ciência, assim como na história da religião, aquelas observâncias cujes significado religioso pode ser descoberto e rastreado são valiosas por si mesmas” (TIELE, 1899, p. 27).

A vasta gama de dados apresenta de imediato um problema. Como os estudiosos da religião conseguirão distinguir o significante do insignificante, o "utilizável” do inutilizável (TIELE, 1899, p. 22). A resposta de Tiele é que nenhum dado deve ser negligenciado, embora se compelido a economizar ele se concentraria nos dados que vêm do próprio "manancial" de cada religião - a saber, mitológico religioso, poético, filosófico e doutrinário - e deixaria as ordenanças religiosas e rituais para investigações posteriores (TIELE, 1899, p. 22). "A Doutrina... oferece a luz mais intensa" porque oferece a chave mestra de explicação para o "culto, o ritual e as cerimônias" que "nada... ensinam" sem um contexto doutrinário (TIELE, 1899, p. 23). A estratégia reversa - que estuda o 
ritual e a ordenança como primordiais - é vista por Tiele como um absurdo (TIELE, 1899, p. 14).

A estrutura taxonômica pela qual Tiele classifica seus dados é definida pela oposição binária do morfológico versus ontológico, por um lado, e sua compreensão característica do desenvolvimento, por outro. O desenvolvimento tem aplicação específica para a primeira categoria (a morfológica) porque as formas religiosas e suas irradiações são os objetos primários de sua investigação. Essa variação é o processo responsável pelo polimorfismo religioso. Em contraste, o gradiente e a direção dessa mutação - a medição do movimento de uma mutação em direção a um telos ainda não alcançado (ou fim) - serve, em última análise, para definir o que a religião é. Assim, a noção tieleana de desenvolvimento tem referentes observáveis, assim como referentes ocultos.

A noção de desenvolvimento de Tiele, como a de Chantepie, é vitalista, mas sem as limitações hegelianas explícitas. Na verdade, é muito semelhante à noção proposta no Essay on the Development of Christian Doctrine, de Newman. 7 Pelo termo "desenvolvimento" Tiele compreende uma noção analogicamente aplicada da história natural à "natureza ou vida espiritual” da humanidade (TIELE, 1899, p. 28). A admissibilidade desta analogia com a religião ele acredita ter surgido da "investigação histórico-antropológica”, bem como por um apelo "a nada menos do que à autoridade do próprio Jesus" em sua comparação com a semente de mostarda (TIELE, 1899, p. 29). Por mais analógico que seja, o desenvolvimento como é aplicado à religião requer um ajuste de definição apropriado. Tiele distingue as características deste desenvolvimento no que se refere à Religião e as religiões. Desenvolvimento religioso - conforme se aplica a ambos - significa:

\footnotetext{
Newman (1974) lista em seu Ensaio sete "notas" ou "testes" que caracterizam o desenvolvimento de uma ideia em oposição à sua corrupção. São eles: (1) preservação da ideia essencial, (2) a continuidade dos princípios sobre os quais a ideia se desenvolveu, (3) o poder de assimilação, (4) a antecipação precoce, (5) a sequência lógica, (6) as adições preservativas e (7) a continuação crônica. Uma comparação ponto a ponto sugere que os "testes" de Newman 1, 2, 3, 4 e 5 \& 6 (juntos) correspondem para às características de Tiele a,b, lei de assimilação c \& e. Embora as características de desenvolvimento de Tiele não sejam discutidas em detalhes, como as de Newman, a semelhança sugere a possibilidade de que ele as tenha emprestado de Newman ou que tanto Tiele quanto Newman estavam se apropriando de uma fonte comum. Que eu saiba, ninguém ainda descobriu a fonte dos "testes" de Newman. (Veja: N. LASH, 1975, para o melhor tratamento das origens intelectuais da ideia de desenvolvimento de Newman.).
} 
a) que a religião individual passando por uma mudança positiva existe como uma "unidade” por trás de seu aparente polimorfismo;

b) que a mudança não é "caprichosa", mas segue uma sequência semelhante a uma lei em que os estágios posteriores crescem a partir dos anteriores;

c) que a religião individual possui um princípio enteléquico em que sua forma final está presente potencialmente em seu estágio inicial;

d) que cada um desses estágios tem "valor, importância e direito de existência"; e) que cada estágio é sublimado - em certo sentido - em um estágio seguinte;

f) que a religião preserva seu genus sobre e contra outros domínios culturais (TIELE, 1899, p. 30-31). A isso ele associa a lei do desenvolvimento, ou seja, esse desenvolvimento só pode ocorrer com vigor se a religião for capaz de assimilar elementos da ecologia social circundante (TIELE, 1899, p. 239-243).

Quando relativo às religiões particulares - as formas que a religião assume - o desenvolvimento pode ser contínuo ou descontínuo, estagnado ou dinâmico, progressivo ou retrógrado, de curta ou longa duração e/ou culturalmente dependente ou independente (TIELE, 1899, p. 31-32). Todas as religiões - como os seres humanos - "têm seus períodos de nascimento, crescimento, florescimento e declínio", mas a religião - como a humanidade evolui indefinidamente (TIELE, 1899, p. 31-32). Aqui, Tiele tem o cuidado de apontar que as mudanças relativas que caracterizam o desenvolvimento das religiões são frequentemente "externas" e não são indicativas da mudança na religião. Tiele aparentemente aceita uma noção de características acidentais dos taxons como a dos naturalistas. Mas para ele não há surgimento espontâneo de características religiosas; elas surgem sempre por meio do projeto e do propósito de humanos que as consideram "a expressão mais adequada da verdade religiosa” (TIELE, 1899, p. 33). Essa seleção guiada de forma inteligente é, em última análise, refinada na eira da história humana, onde ideias e práticas desatualizadas, obsoletas, inaptos e fracos são peneirados (TIELE, 1899, p. 34). Tais mudanças, no entanto, são meros fenômenos que 
manifestam o desenvolvimento, não o desenvolvimento em si. Para que ocorra uma mudança nesses elementos, já deve ter havido uma mudança na consciência ("a disposição, sentimento e atitude mental”) dos humanos responsáveis por ela (TIELE, 1899, p. 35).

Tiele reconhece que essa mudança é um problema do tipo "ovo ou galinha”. Embora ele não deixa claro se as mudanças no sentimento religioso ou na consciência precedem as mudanças na conceituação ou na razão, ele de fato se aventura a afirmar que existe direção causal para a Mudança religiosa. As mudanças nas "disposições gerais da humanidade e...visões da vida e do mundo são refletidas" nas ideias religiosas (TIELE, 1899, p. 35). As características externas podem assim ser lidas como evidências de uma lei interna, vida ou Espírito que manifesta um "avanço contínuo" por meio de seus "avanços temporários” (TIELE, 1899, p. 38).

Ligada como se encontra à consciência humana, a religião acompanha sua evolução. Essa conexão é descrita por Tiele como um dos objetos da ciência da religião. Sua hipótese de trabalho (com base na pesquisa histórica) é que a lei do desenvolvimento da consciência humana é a lei de desenvolvimento da religião (TIELE, 1899, p. 33). Pode parecer que essa admissão de "um desenvolvimento, sujeito a certas leis e produzido por forças residentes" é uma admissão de que existe uma espécie de naturalismo, materialismo ou positivismo, mas ele nega que esse desenvolvimento exclua "a agência" e "a revelação" do sobrenatural não mais do que no reconhecimento do desenvolvimento no mundo físico (TIELE, 1899, p. 51). O desenvolvimento é a revelação. Cabe à ciência da religião provar que o desenvolvimento ocorre e, portanto, explicar os fenômenos religiosos. Mas é “um mistério insolúvel” e além da capacidade de qualquer ciência "para explicar... o que crescimento e vida realmente são" e " como ocorre seu desenvolvimento" (TIELE, 1899, p. 52).

Os táxons de Tiele são governados pela distinção entre as "etapas” ou "estágios" de desenvolvimento e as "direções" de desenvolvimento religioso ligada a diferentes ecologias (TIELE, 1899, p. 54). O termo "estágio" aqui é um pouco enganoso porque sugere uma sequência estrita para o surgimento de formas, ao passo que o que Tiele realmente tem em mente é a segmentação de 
uma estrutura braquiolada (ou cladística) como a de uma genealogia. Os estágios representam posições temporais relativas em uma genealogia indicando a emanação e crescimento das religiões umas em relações as outras (54). Para descrever esses estágios, Tiele prefere a frase "formas de existência" (morphai), construindo cada forma de tal modo que as formas mais desenvolvidas contenham os germes essenciais das formas anteriores (TIELE, 1899, p. 55).

A “direção” do desenvolvimento de uma religião é interpretada por Tiele para indicar a distância (ou gradiente de diferença) dos ramos (ou família de tradições religiosas relacionadas) surgindo de algumas religiões tronco, ancestral ou feixe das ideias-raízes (TIELE, 1899, p. 55). Cada tronco representa uma "elaboração unilateral de uma ideia religiosa (raiz) principal... às suas consequências extremas" expressando o "desenvolvimento religioso" em um determinado período histórico (TIELE, 1899, p. 55). Novamente, Tiele identifica, aqui, outro mecanismo natural que corresponde à noção husserliana de variação de perspectiva, mas é aquela que relaciona a transformação de uma ideia contra as mudanças em sua base histórico-cultural (RYBA, 1991). A própria unilateralidade desse desenvolvimento de ideias básicas significa que outras ideias-raiz, igualmente essenciais, são temporariamente forçadas "no fundo" apenas para emergir como tradições religiosas paralelas quando sua negligência e, portanto, sua indispensabilidade, torna-se aguda (TIELE, 1899, p. 55). As condições históricas determinam se esses ramos independentes encerram, continuam sua direção paralela, ou se juntam (ou reingressam) em outros ramos paralelos (TIELE, 1899, p. 56).

Até agora, Tiele apenas descreveu a natureza do desenvolvimento; ele não descreveu quais descrições podem ser anexadas a qualquer um dos estágios de desenvolvimento ou suas diretrizes. Concordando - presumivelmente, com Chantepie - ao dizer que sua apropriação de Hegel não diminuiu seu "gênio e aprendizado", Tiele rejeita a classificação das religiões de acordo com a filosofia hegeliana descrevendo-a como "um fracasso" e "inútil” devido à imperfeição dos dados (TIELE, 1899, p. 58). Embora ele já tenha feito uma classificação geral e comparações, Tiele argumenta que os dados mostram ainda mais "quantas 
lacunas ainda permanecem" com respeito aos fenômenos religiosos cujo "significado e importância original” ainda não foram descobertos (TIELE, 1899, p. 59). Ele, como Chantepie, modestamente admite que "[todas] as classificações são... provisórias”, seus limites são confusos e muitas vezes sobrepostos (TIELE, 1899, p. 59). Ele, novamente como Chantepie, estabelece um sistema aproximado de classificação que distingue entre religiões da natureza e religiões éticas, seguindo Whitney, Hartman, Caird e outros (TIELE, 1899, p. 60-61). Entre esses dois tipos religiosos, ele vê uma grande clivagem ou divisão no desenvolvimento histórico da religião e uma grande distinção nas idéias principais ou motivos governantes, uma ruptura que foi nada menos que uma revolução religiosa ou mudança catatrófica, embora a religião ética tivesse seu começo embrionário na matriz da religião da natureza e compartilha muitas de suas características (TIELE, 1899, p. 63-65). Em sua subdivisão desses dois estágios, ou "troncos", ele segue o método das bifurcações porfirianas. As religiões da natureza são divididas em: a) religiões de naturezas mais baixas vs. religiões de naturezas mais altas e religiões éticas que são divididas em: b) religiões espiritualistas versus religião da revelação e, finalmente, religião da revelação em religiões nacionalistas e universalistas (TIELE, 1899, p. 120, 148).

Diferenças específicas (ou diferenças nos tipos de desenvolvimento) são associadas por Tiele com as direções de desenvolvimento, mencionadas acima. Por "direção de um desenvolvimento religioso", ele intenciona uma "corrente espiritual que abrange um princípio único de religião, ou alguma ideia religiosa fundamental,... levada às suas consequências extremas” (TIELE, 1899, p. 151). Em termos biológicos, o que Tiele descreve aqui é análogo ao mimetismo biológico ou à modificação de diferentes partes funcionais de modo que elas compartilham a mesma forma aparente. Assim, duas religiões com diferentes níveis de desenvolvimento podem compartilhar características qualitativas semelhantes, enquanto duas religiões no mesmo nível de desenvolvimento podem ser qualitativamente muito diferentes (TIELE, 1899, p. 151). Essa possibilidade resulta do conjunto de vicissitudes históricas, incluindo nacionalidade e origem (TIELE, 1899, p. 151). A direção da religião difere do estágio da religião em que o último não define uma sequência mas uma simples diferença qualitativa baseada nas “ideias raízes” de cada uma. De particular 
importância são as conceituações do absoluto, as relações entre os crentes e o absoluto, e as visões de mundo dos crentes. Aqui, ele faz distinção entre as religiões teantrópicas versos as religiões teocráticas, sendo que as primeiras têm como ideia norteadora a presença do "divino no homem", enquanto as últimas têm como ideia principal a "supremacia de... (o divino) sobre o mundo do homem e da natureza" (TIELE, 1899, p. 156).

O “elemento fixo, permanente e imutável” da religião, "suas características essenciais" , requer algo semelhante, a contraparte natural à noção husserliana de variação de perspectiva - para se tornar aparente. A essência pode ser obtida "a partir das diferentes formas que a religião assumiu ao longo de todo o curso da... história" (TIELE, 1899, p. 54). O que a religião é, se manifesta no "como ela veio a ser" (TIELE, 1899, p. 54). Mas isso não faz da Religião uma função da soma das adaptações das religiões às suas respectivas ecologias. Muito pelo contrário. O que a religião é, se mostra através do esboço parcial de todas as suas possibilidades. O estudo do crescimento e origem da religião pode, de fato, ser paralelo as ciências da "embriologia e biologia" (TIELE, 1899, p. 54). No entanto, a visão de Tiele é uma reversão da noção de que a ontogenia reproduz a filogenia. Não é verdade que cada religião reproduz o desenvolvimento das classes da religião a que pertence. Em vez disso, o desenvolvimento filogenético das religiões é a expressão da essência subjacente, ou para colocá-lo em termos biológicos, a filogenia é a elaboração das possibilidades de raiz, ou genética, da religião, mas sem a possibilidade de mutação genética. É esta variação adaptativa não darwiniana que nos mostra o que a religião é, principalmente em suas formas mais perfeitas. Tiele chega a descrever este objetivo da investigação desta variação adaptativa como a descoberta de uma psicologia religiosa ou ontologia (TIELE, 1899, v. 2, p. 188). Ele usa a palavra “ontologia” para descrever a segunda parte de seus Elementos para contrastá-lo com a história natural (morfologia) constituindo a primeira etapa. "Ontologia” denota o que é imutável, em contraste com as religiões em seu desenvolvimento histórico, enquanto a "fisiologia" designa uma investigação que não é metafísica, mas natural e relacionada com a realização da psicologia humana (TIELE, 1899, v. 2, p. 188). 
Pelo fato de Tiele pensar que as formas mais elevadas de religião revelam sua natureza da mesma maneira que o potencial da bolota se acha mais bem revelado no carvalho maduro, ele interpreta as religiões de revelação universalistas nas suas variáveis teândricas e teocráticas como as mais elevadas e que mostram melhor a essência da Religião, embora nenhuma das duas tenha alcançado uma resolução para essa distinção contrastante (TIELE, 1899, p. 53). Assim, Tiele sugere que o potencial máximo da Religião será a resolução a respeito da questão do teândrico e do teocrático, uma resolução que pode ser encontrada na descrição da religião como a experiência por trás da compulsão à adoração (TIELE, 1899, v. 2, p. 198).

\section{A descontrução chantepieana e tieleana das Ciências da Religião}

Tendo realizado uma síntese, e espero que tenha sido de forma justa, da leitura das concepções chantepieana e tieleana da ciência religiosa, sua estrutura e abordagem taxonômica, gostaria agora de explicar que conclusões podemos tirar dessas noções. É minha opinião que no cerne de ambas as concepções de chantepieana e tieleana sobre as ciências da religião se encontram oposições que causam uma desintegração fundamental. Isso se origina do fato de que se apropriaram de elementos filosóficos incompatíveis. Essas oposições atravessam níveis discursivos, através de discussões de taxonomias intracientíficas e discussões de taxonomias metacientíficas. Com isso, quero dizer que suas ideias sobre a ciência (e as maneiras pelas quais as ciências são classificadas), sejam internamente inconsistentes ou consistentes, se opõem às respectivas taxonomias intracientíficas. Em outras palavras, há um ajuste pobre entre os grandes projetos de sua ciência religiosas e a maneira como esses projetos moldam a taxonomia religiosa.

\subsection{Oposições às noções de uma ciência da religião em Chantepie}

Num artigo muito interessante e bem argumentado apresentado numa conferencia MTSR, Tim Murphy argumentou que os temas hegelianos eram generalizados no início da História da Religião (MURPHY, 1994). Embora ele possa ter exagerado, sua tese em alguns pontos, a importância da filosofia hegeliana para a ciência da religião é inquestionável. Mas sua importância não 
estabelece sua hegemonia total. Aqui, devo argumentar que o fundo intelectual para as apropriações de Chantepie e Tiele da fenomenologia e a ciência não foram simplesmente hegelianas, mas mais complexo e misto. Essas apropriações incluíram filosofias de ciência fora do espectro idealista absoluto.

Em sua Encyclopedia of the Philosophical Sciences, Hegel apresenta um projeto para a organização da ciência que obviamente influenciou Chantepie, como pode ser testemunhado por sua aceitação dos três métodos para estudo da religião, o metafísico, o psicológico e o histórico. ${ }^{8}$ No entanto, eu gostaria de sugerir que uma influência por si só não produz uma filosofia hegeliana. Na Encyclopedia, esta divisão mencionada por Chantepie corresponde à divisão entre (a) Lógica (ou metafísica); (b) Filosofia Natural e (c) Psicologia. Como Murphy corretamente observa, a relação entre as ciências filosóficas e a história é como a relação entre matéria e forma, ou o material tomado como o assunto para análise (MURPHY, 1994). Mas mesmo quando essa metáfora formamatéria é aceita, nem toda a história necessariamente torna-se história filosófica. De acordo com Hegel, a história pode ser realizada de três maneiras: (1) como história original, (2) como história reflexiva e (3) como história filosófica (HEGEL, 1956, p. 1).

A história original é irrefletida e escrita acriticamente de dentro do mundo social habitado (e herdado) pelo historiador. A história reflexiva como história universal é escrita com a intenção de contextualizar eventos contra o pano de fundo de uma nação ou do mundo. História reflexiva como história pragmática uma variedade de história que Chantepie vê vagamente, com razão - é história moralista, uma leitura anaconística do passado de acordo com os valores de hoje, a fim de colher lições morais. A história reflexiva como história crítica é a história da história. Por fim, a história reflexiva como história das idéias é a tentativa de apresentar uma posição abstrata, mas de acordo com a história de

\footnotetext{
${ }^{8}$ Curiosamente, Chantepie nem aborda a possibilidade de que uma abordagem natural-científica ao estudo da religião possa ser abordado ao longo dos textos hegelianos, mas isso provavelmente tem mais a ver com a forma como Hegel conceitua as ciências naturais - A abordagem hegeliana da filosofia natural já tinha se tornado obsoleto por volta do século 19 filosofias da ciência - e a maneira como ele coloca o estudo da história fora da Enciclopédia, exceto na medida em que possa ser tratada filosoficamente. Isto é provavelmente também relacionado ao fato de que Hegel não vê nenhum papel para a filosofia da ciência natural no estudo da religião, exceto como um preâmbulo para testar as categorias da Lógica no mundo natural. Mesmo assim, há vários lugares na segunda parte da Enciclopédia, onde há discussões de desenvolvimento natural que têm ressonâncias no Manual de Chantepie. Em muitos casos, essas passagens são derivadas de pesquisas de naturalistas anteriores, a pátina do vocabulário hegeliano sendo usado de forma transparente por eles.
} 
diferentes setores da cultura - arte, direito, religião - e sem uma única noção subjacente de sua unidade. Por fim, a história filosófica é a história estudada como um processo racional (ou sistema unitário) no qual o Espírito se realiza (HEGEL, 1956).

É claro, no entanto, que embora Chantepie pretenda tratar os materiais históricos em seu Manual como algo além da história original, ele excluiu a possibilidade de tratar a religião de acordo com a história filosófica. Porque isto acontece? É porque Chantepie aceita as divisões disciplinares hegelianas, sem aderir ao aparato das categorias lógico-metafísicas hegelianas. Rejeitando como fez, as especificidades do esquema evolutivo hegeliano, e adiando, desse modo, a análise filosófica dos dados religiosos, Chantepie parecia estar tentando derivar um novo conjunto de categorias com base nos dados. De fato, as divisões de suas seções fenomenológicas, históricas e etnográficas mostram uma estruturação dos estudos religiosos, na maioria dos pontos, de modo diferentes daqueles sugeridos pela Escola hegeliana e muitas vezes dependentes de pesquisas de estudiosos fora dela. Chantepie parece, assim, paradoxalmente, propor uma revisão da filosofia hegeliana da religião com base em dados empíricos (e consenso acadêmico) enquanto, ao mesmo tempo, sugerindo que os métodos hegelianos gerais de análise da religião - o metafísico, o psicológico e o histórico - são abordagens superestruturais corretas (embora vazias). Ao colocar a análise histórica fora da história filosófica, ele a situa além da filosofia hegeliana. Porque ele rejeitou a história original e porque ele colocou suas pesquisas históricas fora da história filosófica, por inferência a variedade de história que Chantepie pretende, pareceria ser algum tipo de história crítica baseada em traços essenciais das religiões.

Além disso, algo muito claramente não hegeliano está presente na colocação da fenomenologia de Chantepie dentro do estudo da religião como a ponte entre a história e a filosofia. Ele parece - do ponto de vista hegeliano haver colocado o carro na frente dos bois. Especificamente, essa sequência é estranha. Seria de se esperar que Chantepie primeiramente elaborasse uma filosofia da religião na qual viesse a basear as categorias de análise taxonômica. Na verdade, esta é a sequência no corpus hegeliano. 
Na Enciclopédia, a fenomenologia encontra-se na terceira parte, aquela dedicada à psicologia filosófica (a filosofia da mente). Isto pressupõe as categorias formais da primeira parte - a Lógica - e a aplicação dessas categorias à natureza (a segunda parte). Em sua obra "Lectures on the Philosophy of Religion”, Hegel deixa clara sua intenção de incluir a ciência da religião dentro da filosofia. Como ele assevera,

A ciência da religião é uma ciência dentro da filosofia (grifo meu); assume, até aqui, a existência de outras divisões do estudo filosófico, sendo assim um resultado. Do ponto de vista filosófico, já estamos aqui em posse de um resultado que flui de premissas previamente estabelecidas, que agora ficaram para trás. Nós podemos, no entanto, buscar auxílio na nossa consciência ordinária, aceitando os dados assumidos de modo subjetivo e começando a parti daí. (HEGEL, 1974, p. 89-90).

Chantepie ignora esta instrução hegeliana. Em seu Manual, Chantepie coloca a fenomenologia, primeiro, na ciência religiosa, e usa suas categorias formais para moldar os dados históricos e etnográficos. Isso significa que a fenomenologia de Chantepie não se sustenta em nenhuma base filosófica. Como o próprio autor admite, as categorias resultantes das descobertas fenomenológicas não são produtos da filosofia da religião, mas são derivados de descobertas de outros estudiosos e desse modo ela tem sido submetida a um processo de seleção que é exclusivamente chantepieano, mesmo que algo de hegeliano possa ser detectado. Isso me sugere que a "estrutura sombra" de outra noção de ciência é visível por detrás das considerações do arcabouço do pensamento hegeliano. 9

Para Chantepie, alegar que sua fenomenologia era (a) histórica, (b) não filosófica e (c) preocupada apenas com características religiosas objetivas e, ao mesmo tempo, afirmar que estava seguindo o modelo hegeliano de ciência é contraditório, uma vez que Hegel descreve a fenomenologia na sua preocupação especificamente com a subjetividade da consciência (ver acima e

\footnotetext{
9 Pode-se tentar salvar a natureza hegeliana da Ciência da Religião de Chantepie, argumentando que sua colocação da fenomenologia da religião espelha a colocação da fenomenologia da mente na sequência hegeliana das ciências filosóficas como uma indicação da intenção de Hegel a começar a partir da consciência comum, aceitando seus dados de maneira subjetiva. Também fica claro, contudo que Chantepie está consciente da peculiaridade de se incluir a fenomenologia em uma obra estritamente histórica e não filosófica.
} 
Hegel, 1971, p. 151-178). Inversamente, mesmo que seja garantido que Chantepie tenha secretamente introduzido a filosofia hegeliana como o princípio formal para estruturar o material histórico, a objetividade de sua noção de fenomenologia (e muitas das categorias que ele emprega) não são hegelianas na sua origem. Pode-se também chamá-lo de aristotélico porque ele emprega a distinção forma-matéria! Assim se mostra a natureza dividida e fragmentada do projeto de Chantepiano ${ }^{10}$.

\subsection{Oposições entre a noção de Chantepie da Ciência da Religião e sua taxonomia das religiões}

É fácil especificar as oposições entre a noção chantepieana de uma ciência da religião e sua taxonomia afirmando que, além da distinção entre a essência geral (da religião) e as manifestações (da religião), e além das alusões gerais às noções hegelianas de desenvolvimento, os elementos particulares de comparação que ele seleciona não são hegelianos, mas são derivados da etnografia e da história formadas por outras filosofias. Como ele consegue reivindicar a manutenção da estrutura científica hegeliana no seu empreendimento, enquanto a esvazia da sua aplicabilidade concreta (tal como pode ser) é um mistério. Porque ele admite um subconjunto da visão consensual da religião, isso sugere que as visões da ciência (tacitamente) em jogo são preferíveis. Mas quais eram essas visões? E por que Chantepie colocou a fenomenologia em primeiro lugar em sua ciência da religião?

\subsection{Oposições na noção de ciência da religião em Tiele}

Embora mais sofisticado e mais bem concebido do que a ciência da religião chantepieana, a ciência da religião de Tiele manifesta uma grande variedade de complicações. Aqui, apesar da evocação de características estruturais semelhantes como essência, manifestação e evolução, o discurso de Tiele contra Murphy - não é principalmente moldado pela filosofia hegeliana, mas pela união de vocabulários e explicações naturalistas e vitalistas. No modelo tieleano de ciência religiosa, a principal oposição é entre seu desejo de delinear

${ }^{10}$ Ver Hegel (1975; 1970; 1971). 
uma ciência naturalista da religião e sua incapacidade de se despojar de um vitalismo que é transferido metaforicamente de modelos da ciência biológica para o domínio da ciência religiosa.

Como Chantepie, Tiele pretende fornecer uma descrição de uma ciência incipiente da consciência humana que seria tão naturalista quanto qualquer uma das ciências culturais. Mas esta intenção é contrariada por uma contravenção em que se evita o materialismo implícito em uma abordagem naturalista em favor de um princípio oculto importado da biologia vitalista, a saber, a noção de uma enteléquia. ${ }^{11}$ Pode-se argumentar que na época em que Tiele escreveu, essa ciencia era credível. E assim foi, no sentido de que o vitalismo teve muitos seguidores. Mas a própria intenção de Tiele de excluir princípios metafísicos, mesmo os teoricamente postulados, entrou em conflito com esta teoria.

O vitalismo de Tiele é mais claramente evidenciado em sua lista de características do desenvolvimento religioso e sua discussão das leis do desenvolvimento. As seis características do desenvolvimento - (1) unidade na religião (2) mudança semelhante à lei, (3) enteléquia do potencial religioso, (4) o valor de cada estágio da existência, (5) sublimação de estágios anteriores em posteriores e (6) preservação do gênero - e a lei de assimilação formam um conjunto de características paralelas às marcas ou notas de desenvolvimento que podem ser encontradas em Newman's Essay on the Development of Christian Doctrine e, talvez, indicando uma fonte comum na filosofia da biologia do século 19. As dificuldades com esses princípios são numerosas.

Primeiramente, há um problema relacionado à aplicação dessas caracteristicas e leis. Como é o caso com as marcas de desenvolvimento doutrinário de Newman, não está inteiramente claro se elas se aplicam a uma religião hipostatizada (ou no caso de Newman, a doutrina cristã) ou se elas são

\footnotetext{
${ }^{11}$ A noção de uma enteléquia é de origem aristotélica. O termo enteléquia é interpretado por Aristóteles como o processo de conclusão ou o processo de ser em direção à conclusão. A alma é descrita por Aristóteles como sendo a primeira enteléquia do corpo, o que implica que o fim primordial do funcionamento do corpo está na sua alma. A teleologia dessa noção é óbvia. (Ver Aristóteles, De Anima, 2: 412b.) Tiele transfere a metáfora biológica para aplicá-la ao motor ou espírito oculto que impulsiona a religião por meio da consciência humana.
} 
aplicadas à consciência humana. ${ }^{12}$ Apesar das afirmações de Tiele de que a ciência da religião é uma ciência da consciência, sua discussão se concentra quase exclusivamente nos artefatos dessa consciência, a tal ponto que, quando chega a hora dele revelar exatamente o que é a essência da Religião, ele a descreve como espiritualidade manifestada em adoração (2:195-207) - Isso parece ser uma conquista muito pobre para uma ciência que promete tanto.

Em segundo lugar, a metáfora que ele aceita para o desenvolvimento da religião é essencialista e teleológica, sugerindo que a perfeição final da religião está contida in potentia em suas formas individuais (ou religiões) e por uma enteléquia encontrará sua realização final. Isso sugere que sua direção de desenvolvimento é sempre positiva. Ao preferir um modelo de desenvolvimento orgânico herdado de Linnaeus, Tiele rejeita totalmente o materialismo da metáfora darwiniana. A religião deve existir como um gênero fixo, religiões elaborando as características pré-estabelecidas mantidas potencialmente. Ele não permitirá que as religiões sejam levadas mecanicamente em seu desenvolvimento pelo ambiente à mutação, extinção e / ou sobrevivência, mas prefere descrever o processo de evolução da religião como, em última análise, misterioso e vitalista. Em última análise, isso enfraquece seu desejo de evitar a metafísica e, assim, criar uma disciplina no mesmo nível das ciências culturais.

Em terceiro lugar, Tiele explica a distinção entre essência e manifestação à luz da metáfora teleológica vitalista. Em vez de construir uma descrição da essência da religião nominalisticamente, empiricamente e ou com base nas propriedades formais descobertas nos dados, Tiele começa com uma compreensão (aparentemente) realista da essência das religiões como um potencial preexistente nas religiões. Isso ele tenta descobrir através da religião histórica mais desenvolvida. Ele é capaz de fazer isso apenas porque ele já estabeleceu que o desenvolvimento positivo é uma função do tempo de modo que, o que vier depois é o melhor. Mas isso aprisiona Tiele em um círculo

\footnotetext{
${ }^{12}$ Nicholas Lash atribui a tendência de ler a psicologia de Newman no Ensaio como uma projeção de alguns de seus comentadores como Walgrave e Simonin. Mas eu gostaria de sugerir que Newman e Tiele convidam a essa leitura, uma vez que se compreenda que as noções de instrumentalidade mediadora do desenvolvimento são a consciência humana. É porque eles alternam entre a consciência humana e as ideias hipostatizadas no desenvolvimento que a confusão resulta. Em ambos os casos, contudo, uma influência oculta é postulada no trabalho da mente humana no sentido de fins religiosos. Ver N. Lash (1975).
} 
conceitual. Como pode o desenvolvimento da religião ser avaliado sem já ter chegado a alguma noção do para onde a religião está indo? E como isso pode ser mensurado sem ter algum conhecimento da esssencia da religião? E, novamente, como essa essência pode ser conhecida sem alguma noção de para onde a religião está indo? A circularidade da avaliação de Tiele do desenvolvimento religioso é óbvia.

\subsection{Oposições entre a noção de ciência da religião de Tiele e sua taxonomia das religiões}

A distinção de Tiele entre as divisões morfológicas e ontológicas de sua ciência da religião pressupõe, como a de Chantepie, que os dados históricos e etnográficos já foram "preparados” por outros especialistas na área. Aqui, Tiele, como Chantepie, coloca o morfológico (ou taxonômico) como primário para investigações subsequentes. Apenas Tiele continua sua exposição envolvendo-se em uma descrição mais longa do termo filosófico (a parte ontológica), uma parte que Chantepie coloca fora do escopo de sua ciência.

Sem dúvida, a parte morfológica de seus Elementos que é a mais bemsucedida, é um resultado do sucesso dos esforços dos etnógrafos e historiadores que o precederam; convence apenas por sua abundância de dados e pelos princípios que ele emprega para preencher suas categorias taxonômicas. Nada inerente aos dados sugere precisamente o modelo de desenvolvimento que Tiele propõe. Aqui está uma questão de os dados serem tão abundantes que muitos exemplos podem ser colocados apropriadamente. A seção ontológica, potencialmente a seção mais interessante, é também a mais desprovida de fecundidade investigativa, uma vez que suas conclusões demasiadamente atenuadas se tornam inúteis para qualquer projeto de pesquisa.

\subsection{A filosofia da ciência ocultada por trás das ciências da religião chantepieana e tieleana}

É minha opinião que as declarações contraditórias que Chantepie e Tiele fazem sobre suas ciências da religião se originam em suas intenções de 
enquadrar uma filosofia oculta da ciência com seus pressupostos metafísicos mais aparentes. Como os historiadores do estudo da religião tem observado as origens hegelianas da história das religiões, eles persistiram em pensar que esse é o único modelo segundo o qual os primeiros estudiosos da religião projetaram sua ciência. Tenho tentado mostrar, entretanto, que no arranjo e na intenção existem algumas contradições significativas entre a maneira como Tielee Chantepie estruturam uma ciência da religião e o arranjo hegeliano. Gostaria ainda de sugerir que nem Chantepie nem Tiele chegaram as estruturas a que chegaram sem qualquer auxilio, mas que dependeram de uma concepção estrutural científica que era mais antiga do que a de Hegel e mais firmemente fundamentada no modo como os cientistas conduziam a pesquisa empírica no século 19.

Descrevi esse modelo, em suas várias encarnações, em meu livro The Essence of Phenomenology and Its Study of Religion (1991). Foi um - senão o modelo persistente para descrever o arranjo da investigação científica discutido por três filósofos anglófonicos da ciência: John Robison (1739-1805), William Hamilton (1788-1856) e William Whewell (1794-1866). Todos esses três pensadores propuseram divisões da ciência que tem amplas correspondências entre si. Porque dois deles também eram cientistas naturais - Robson era um professor de filosofia natural em Edimburgo e Whewell um professor de mineralogia do Trinity College Cambridge - esses esquemas foram provavelmente tentativas para organizar a prática científica de então.

Para Robison, a ciência consistia em fenomenologia, taxonomia e etiologia; para Hamilton, era fenomenologia, nomologia e ontologia; e para Whewell era uma divisão em fenomenologia, taxonomia, etiologia e teoria (ROBISON, 1798; HAMILTON, 1851; WHEWELL, 1967; RYBA, 1991). Cada um desses pensadores acreditava que a ciência deveria proceder da descrição, à classificação de acordo com as propriedades formais de objetos, para a descoberta de regularidades semelhantes a leis e, finalmente, para a construção de grandes teorias com amplo poder preditivo. 
Penso que algo semelhante a esse esquema da descoberta científica foi assumido por Chantepie e Tiele para refletir a prática científica natural e assim se tornou condição sine qua non para a construção de uma ciência da religião. Mas também porque eles se apegaram às noções especulativas hegelianas mais óbvias, suas formulações foram rompidas com oposições. Uma evidência primária para essa "sombra" da filosofia da ciência encontra-se na sequência não hegeliana de disciplinas na ciência da religião de Chantepie: Fenomenologia-Etnografia-História. Mas também está presente em seu impulso para classificar as matérias-primas da história e etnografia, objetivamente, de acordo com princípios taxonômicos de origem não hegeliana. Certamente, ele foi influenciado pela abrangência do sistema hegeliano, e por seu vocabulário e princípios estruturais, mas sua abordagem se orientou no sentido de um arranjo mais solidamente ancorado nas ciências empíricas.

No caso de Tiele, os termos "morfologia" e "ontologia" - e sua sequência espelham mais de perto a estruturação inglesa de Ciência. Ele está mais próximo de aceitar uma ciência naturalista da religião em analogia com as ciências culturais, mas a esterilidade de sua ciência proposta é o resultado de sua incapacidade de transformá-la em uma sequência de métodos empíricos que não pressuponham princípios ocultos.

\section{Conclusão}

Diante da possibilidade de uma abordagem naturalista da ciência da religião - que se baseia em modelos científicos naturais - nem Chantepie nem Tiele conseguiram abandonar certas salvaguardas metafísicas. Para Chantepie e Tiele, esses elementos estavam ligados com sua valorização da Religião e seus meios para sua proteção. Ao mesmo tempo, eles estavam cientes de que uma ciência da religião que prometiam resultados científicos não era impossível. Eles optaram por ter ambas as formas - propor uma ciência da religião, mas para proteger suas caras premissas metafísicas. $\mathrm{O}$ resultado desta incapacidade foi a formulação de ciências sincréticas da religião marcando pontos médios na passagem de uma teologia para uma ciência religiosa naturalista. Ainda hoje, esse sincretismo continua no estudo da religião. 


\section{REFERÊNCIAS}

ARISTOTLE. The Complete Works of Aristotle. Princeton: Princeton University Press, 1984.

BRAUN, W.; MCCUTCHEON, R. T. (ed.). Guide to the Study of Religion. New York: Cassell, 2000.

CASSIRER, E. The Problem of Knowledge: Philosophy, Science and History Since Hegel. New Haven: Yale University Press, 1974.

CHANTEPIE de la Saussaye, P.D. Manual of the Science of Religion. London: Longmans, Green and Co, 1891.

GHISELIN, M. T. Metaphysics and the Origin of Species. Albany: SUNY Press, 1997.

GILSON, E. From Aristotle to Darwin and Back Again: A Journey in Final Causality, Species, and Evolution. Notre Dame: University of Notre Dame Press, 1984.

GOETHE, J. W. V. Scientific Studies. New York: Suhrkamp, 1988.

HAMILTON, W. Lectures on Metaphysics and Logic. Edinburgh: William Blackwood and Sons, 1851.

HEGEL, G. W. F. Encyclopedia of the Philosophical Sciences in Outline and Critical Writings. New York: Continuum, 1990.

HEGEL, G. W. F. Hegel's Logic: Part One of the Encyclopedia of the Philosophical Sciences (1830). Oxford: The Clarendon Press, 1975.

HEGEL, G. W. F. Hegel's Philosophy of Mind: Part Three of the Encyclopedia of the Philosophical Sciences (1930) and the Zusatze of 1845. Oxford: The Clarendon Press, 1971.

HEGEL, G. W. F. Hegel's Philosophy of Nature: Part Two of the Encyclopedia of the Philosophical Sciences (1830) and the Zusatze (1847). Oxford: The Clarendon Press, 1970.

HEGEL, G. W. F. Lectures on the Philosophy of Religion. London: Routledge and Kegan Paul, 1974.

HEGEL, G. W. F. Phenomenology of Spirit. New York: Oxford University Press, 1979 .

HEGEL, G. W. F. The Philosophy of History. New York: Dover Books, 1956.

HEIDEGGER, M. Phenomenology and Theology. In: The Piety of Thinking: Essays by Martin Heidegger. Bloomington: Indiana University Press, 1976. p. 3-21. 
HOENIGSWALD, H. M. and L. F. Wiener (ed.). Biological Metaphor and Cladistic Classification: An Interdisciplinary Perspective. Philadelphia: University of Pennsylvania Press, 1987.

HULL, D. Philosophy of Biological Sciences. Englewood Cliffs: Prentice-Hall, 1974 .

JASTROW, M. J. The Study of Religion. Chico: Scholars Press, 1981.

JORDAN, L. H. Comparative Religion. Atlanta: Scholars Press, 1986.

LASH, N. Newman on Development: The Search for Explanation in History. London: Sheed and Ward, 1975.

MAYR, E. The Growth of Biological Thought: Diversity, Evolution and Inheritance. Cambridge, Mass.: Harvard University Press, 1982.

MURPHY, T. Wesen und Erscheinung in the History of the Study of Religion: A Poststructuralist Perspective. Method \& Theory in the Study of Religion, v. 6, n. 2, p. 119-146, 1994.

NEWMAN, J. H. An Essay on the Development of Christian Doctrine. Baltimore: Penguin Books, 1974.

PADEN, W. E. Elements of a New Comparativism. Method \& Theory in the Study of Religion, v. 8, n. 4, p. 5-14, 1996.

PADEN, W. E. Religious Worlds: The Comparative Study of Religion. Boston:

Beacon Press, 1994.

ROBISON, J. Philosophy. In: Encyclopaedia Britannica, 3rd Edition, 1798.

RYBA, T. The Essence of Phenomenology and Its Meaning for the Scientific Study of Religion. New York: Peter Lang, 1991.

SMITH, J. Z. Drudgery Divine: On the Comparison of Early Christianities and the Religions of Late Antiquity. Chicago: University of Chicago Press, 1994.

SMITH, J. Z. Map is Not Territory: Studies in the History of Religions. Chicago: University of Chicago Press, 1993.

STACE, W. T. The Philosophy of Hegel. New York: Dover, 1955.

TIELE, C. P. Elements of the Science of Religion. New York: Charles Scribner's Sons, 1899.

TIELE, C. P. Outlines of the History of Religion. London: Kegan Paul, Trench, Trubner \& Co., Ltd, 1896.

WHEWELL, W. The Philosophy of the Inductive Sciences Founded Upon Their History. New York: Johnson Reprint Corporation, 1967. 